\title{
Implementation of Sharia Compliance in Murabaha Contract at Bank Syariah Mandiri Ponorogo
}

\author{
Mohammad Ghozali ${ }^{1}$, Abdul Hafidz Zeid ${ }^{2}$, Roifatus Syauqoti ${ }^{3}$, Ika \\ Prasetyaningsih ${ }^{4}$ \\ mohammadghozali@unida.gontor.ac.id ${ }^{1}$, abuafadh@unida.gontor.ac.id ${ }^{2}$, \\ roifatussyauqi@gmail.com³ zafeenaaisyah@gmail.com ${ }^{4}$
}

Universitas Darussalam Gontor, Ponorogo, Indonesia ${ }^{1,2,3,4}$

\begin{abstract}
Sharia Banking is a business entity that collects funds from the public and channels them back based on Islamic sharia law principles, which are required to fulfill sharia compliance principles. Sharia compliance is an important pillar in the development of Islamic banking and at the same time becomes a fundamental as a differentiator between Islamic banks and conventional banks. One product of Islamic banks that causes the perception of "the same" is the murabaha contract. This study concludes that the existing murabaha contract at Bank Syariah Mandiri is not the same as that of a conventional bank, because this bank has complied with all the provisions stipulated by the National Sharia Board. Bank Syariah Mandiri Ponorogo also minimizes the misuse of funds in murabahah contracts by using a wakalah contract only for price negotiations not for purchasing goods.
\end{abstract}

Keywords: Bank Syariah, Sharia compliance, Murabahah

\section{Pendahuluan}

Kepatuhan Syariah (Sharia compliance) merupakan pondasi yang sangat fundamental yang harus dilaksanakan oleh seluruh perbankan syariah dalam operasionalnya namun faktanya, implementasi sharia compliance masih sering dipertanyakan oleh nasabah. Masalah kepatuhan syariah ini menimbulkan isu bahwa produk, SDM, serta operasional bank syariah masih berkaca pada bank konvensional.[1] Hal ini menunjukan bahwa bahwa masyarakat memiliki persepsi yang sama antara bank syariah dan bank konvensional.[2]

Salah satu penyebab munculnya persepsi "sama" tersebut adalah produk murabahah yang lebih mendominasi dibandingkan dengan produk-produk lainnya. Hal tersebut dikarenakan produk murabahah di bank syariah menggunakan prinsip kehati-hatian yang tinggi dan standar sehingga minim risiko, dibandingkan dengan produk bagi hasil yang sangat tinggi tingkat risiko dan kerugiannya. Kelebihan yang dimiliki produk murabahah menjadikannya sebagai produk yang unggul dalam penawaran produk pembiayaan di bank syariah.[3]

Murabahah menuai berbagai kritik karena perbankan syariah mengutamakan produk murabahah dibandingkan produk berbasis bagi hasil dengan akad musyarakah dan mudharabah, bahkan banyak yang menjuluki bank syariah dengan bank murabahah. Yang pada praktiknya telah mengalami berbagai modifikasi menyesuaikan permintaan nasabah. 
Terkadang modifikasi tersebut tidak sesuai dengan kaidah dalam fiqih sehingga tak sedikit yang menyamakannya dengan kredit di bank kovensional.

Modifikasi terhadap akad murabahah terkadang menyebabkan bank syariah tidak patuh pada prinsip syariah (sharia compliance). Padahal aspek konsistensi penerapan syariah compliance sangat berpengaruh pada animo nasabah untuk memilih bank syariah.[4] Hal ini menunjukan bahwa pelaksanaan sharia compliance yang dinilai kurang optimal, menyebabkan rendahnya kepercayaan masyarakat.[5]

Dalam jangka panjang kepercayaan nasabah sebagai indikator kinerja perbankan berdampak pada meningkatnya komitmen nasabah yang menghasilkan peningkatan market share perbankan syariah [6] Namun faktanya, market share perbankan syariah Indonesia baru mencapai 5.13\% dengan jumlah penduduk mayoritas umat Islam, dengan potensi $87.18 \%$ dari keseluruhan penduduk Indonesia. Ini membuktikan kurangnya kepercayaan masyarakat terhadap bank syariah.[7]

Sehingga eksistensi implementasi sharia compliance menjadi kebutuhan masyarakat. Ketidakjelasan terhadap jaminan kepatuhan syariah dari segi operasional perbankan syariah dan lembaga keuangan syariah non-bank, menguatkan persepsi bahwa bank syariah dan bank konvensional tidak memiliki perbedaan.[8]

\section{Sharia Compliance Perbankan Syariah}

Sharia compliance adalah ketaatan bank syariah dalam beroperasi berdasarkan prinsip-prinsip syariah Islam khususnya menyangkut tentang muamalah secara islami. Ketaatan tersebut tercerminkan dari produk-produk yang ditawarkan yang bebas riba dan menggunakan prinsip bagi hasil.[9] Sharia compliance merupakan salah satu bagian dari tata kelola lembaga dan juga merupakan bagian dari manajemen risiko yang berstandar internasional yang ditetapkan oleh Islamic Financial Service Board.[10]

Sharia compliance adalah bentuk pemenuhan keseluruhan prinsip-prinsip syariah dalam operasional lembaga keuangan syariah yang menunjukkan integritas, karakteristik, dan kredibilitas di bank syariah. Kepatuhan terhadap prinsip syariah juga mendukung kepatuhan terhadap ketentuan Bank Indonesia yang diwujudkan dalam bentuk budaya patuh pada nilai, perilaku dan tindakan.[11] Dimana pelaksanaan kebijakan, sistem, ketentuan dan prosedur, serta kegiatan operasional oleh bank syariah yang sesuai dengan ketetapan Fatwa DSN-MUI, Bank Indonesia, dan peraturan perundang-undangan yang berlaku menjadi fokus utama dari fungsi kepatuhan syariah.[12]

Dewan Pengawas Syariah (DPS) merupakan ciri khas bank syariah juga sebagai lembaga pengawas bank syariah yang menjamin terlaksananya sharia compliance di lembaga perbankan dan keuangan syariah. Keberadaan DPS dalam mengawasi lembaga keuangan syariah telah diatur dalam undang-undang. [13]

\section{Akad Murabahah dalam Perbankan Syariah}

Asal kata murabahah dari bahasa arab yang berarti keuntungan,[14] Murabahah merupakan salah satu bentuk pembiayaan di bank syariah yang paling banyak diminati masyarakat.[15] Penetapan harga jual dalam pembiayaan murabahah berlandaskan pada harga pokok perolehan barang ditambah sejumlah margin keuntungan bank.[16] Bank dan nasabah tidak boleh merubah harga jual yang telah disepakati di awal akad masa waktu pembiayaan.[17]

Akad murabahah merupakan salah satu bentuk jual beli yang diperbolehkan oleh Allah berlandaskan pada Surat al-Baqarah ayat 275.[18] Selain dijelaskan dalam ayat 275 surat al-Baqarah, sebuah hadith yang diriwayatkan oleh Hakim juga menjelaskan bahwa Rasulullah s.a.w ketika ditanya tentang pekerjaan yang paling baik maka salah satunya beliau 
menjawab jual beli yang mabrur.[19] Dari ayat dan hadist tersebut menjelaskan bahwa Allah melarang untuk menyamakan hukum jual beli dan riba.[20] Allah mengharamkan riba dan menghalalkan jual beli. Jual beli yang halal menurut peraturan yang diakui oleh syariat adalah jual beli yang dilakukan dengan saling suka atau saling rela di antara pihak pembeli dan pihak penjual.

Sedangkan secara hukum positif murabahah adalah pembiayaan bank syariah yang secara umum dasar hukum rekstrukturisasi akad pembiayaan adalah Pasal 36 UU perbankan syariah, dan secara khusus adalah pasal 2 ayat (1) PBI No.10/18/PBI/2008 dan Butir 1 angka 4 SEBI No.10/34/DPBS/2008[21]. Ketiga dasar hukum tersebut dalam aplikasi akad murabahah harus memperhatikan beberapa hal terkait prinsip-prinsip syariah yang merestrukturisasi diantaranya:

Pertama prinsip tidak saling merugikan antara bank dan nasabah, segala kegiatan operasional usaha harus dilakukan oleh bank harus yaitu dengan cara-cara yang tidak menimbulkan kerugian antara keduanya.

Kedua, prudential principle yaitu keyakinan bank atas kemampuan serta kemauan nasabah dalam memenuhi kewajiban tepat pada waktunya tercantum dalam pasal 22 Ayat 1 UU perbankan syariah), serta prinsip mengenal nasabah yang dianalisis menggunakan penilaian terhadap 5C yaitu kepribadian (character), kemampuan (capacity), kondisi aset dan modal nasabah (capital), jaminan apabila nasabah wanprestasi (collateral), faktor eksternal yang berpengaruh pada kegiatan usaha nasabah (conditional of economic).

Ketiga, prinsip syariah, yaitu akad murabahah dilaksanakan berdasarkan fatwa DSNMUI.[22] Adapun fatwa No.04/DSN-MUI/IV 2000 tentang murabahah merupakan dasar pelaksanaan akad murabahah.

Keempat, prinsip dasar ekonomi Islam yaitu pengharaman riba, gharar, maysir, yang merupakan bentuk kepatuhan terhadap hukum Islam. Disamping itu, untuk menghindari adanya unsur haram dalam pelaksanaan operasional dibutuhkan sistem pengawasan internal yang ketat, dan perlu dilaksanaan secara efektif untuk mengindari kecurangan dan pelanggaran terhadap kepatuhan syariah sebagai upaya agar bank dan nasabah tidak ada yang dirugikan.[23]

Penerapan keempat prinsip di atas merupakan wujud kepatuhan perbankan syariah untuk mendukung pelaksanaan manajemen resiko perbankan dalam melaksanakan prudential principles (kehatian-hatian) sesuai dengan peraturan perundang-undangan yaitu pasal 36 perbankan syariah dalam melaksanakan akad pembiayaan. Berikut skema implementasi akad murabahah di perbankan syariah: 


\section{Aplikasi Teknis Pembiayaan Perbankan}

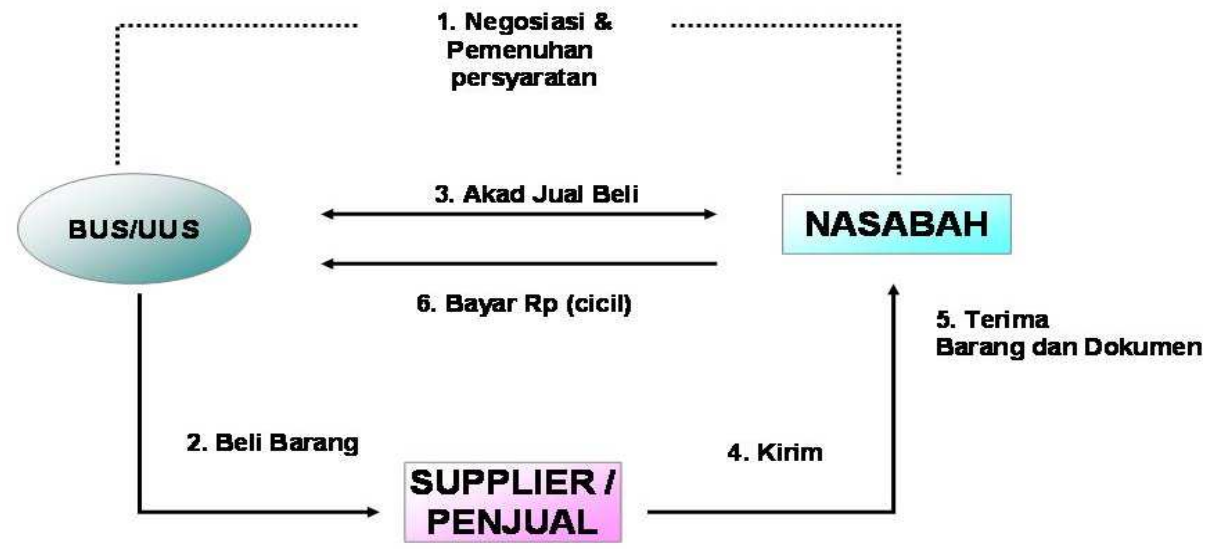

Gambar 1. Skema Akad Murabahah

Keterangan:

a. Negosiasi antara bank dan nasabah tentang akad jual beli yang akan dilangsungkan, serta pemenuhan dokumen yang menjadi syarat pengajuan pembiayaan.

b. Atas dasar negosiasi diatas, maka bank syariah membelikan barang yang diinginkan nasabah dari supplier.

c. Akad jual beli antara bank syariah (penjual) dan nasabah (pembeli).

d. Bank meminta supplier untuk mengirimkan barang kepada nasabah.

e. Serah terima barang dan dokumen kepemilikan dari supplier kepada nasabah.

f. Nasabah melakukan pembayaran kepada bank syariah dimana pembayaran sering kali dilakukan secara angsuran.[24]

\section{Implementasi Kepatuhan Syariah (Sharia Compliance) Akad Murabahah di Bank Syariah Mandiri Ponorogo}

Akad murabahah merupakan pembiayaan berdasarkan akad jual beli dimana bank membelikan barang yang diinginkan nasabah kemudian menjual barang tersebut kepada nasabah dengan harga pokok ditambah keuntungan margin yang disepakati oleh keduanya.[25] Aplikasi murabahah yang ada di Bank Syariah Mandiri Ponorogo diawali dengan pengajuan pembiayaan dari nasabah untuk membeli rumah yang diinginkan dan membawa kelengkapan dokumen yang menjadi syarat pengajuan pembiayaan. Tahap selanjutnya yaitu nasabah diuji kelayakannya menggunakan prinsip 5C untuk melihat kemampuan nasabah dalam melunasi kewajibannya. Tahap setelah nasabah dianggap layak yaitu survei lapangan yang dilakukan oleh pihak bank untuk memastikan kebenaran dokumen. Uji kelayakan ini sangat penting bagi bank sebelum menerima permohonan pembiayaan dari nasabah untuk menghindari adanya kredit macet.

Akad murabahah yang diaplikasikan oleh Bank Syariah Mandiri Ponorogo tidak berdiri sendiri melainkan digabungkan dengan akad wakalah yang dikenal dengan akad murabahah bil wakalah [26] sebagaimana yang ada di bank syariah lainnya. Pada pelaksanaannya Bank Syariah Mandiri Ponorogo menggunakan akad wakalah untuk memberi kuasa kepada nasabah dalam negosiasi harga saja bukan dalam pembelian barang. Berikut skema akad tersebut: 


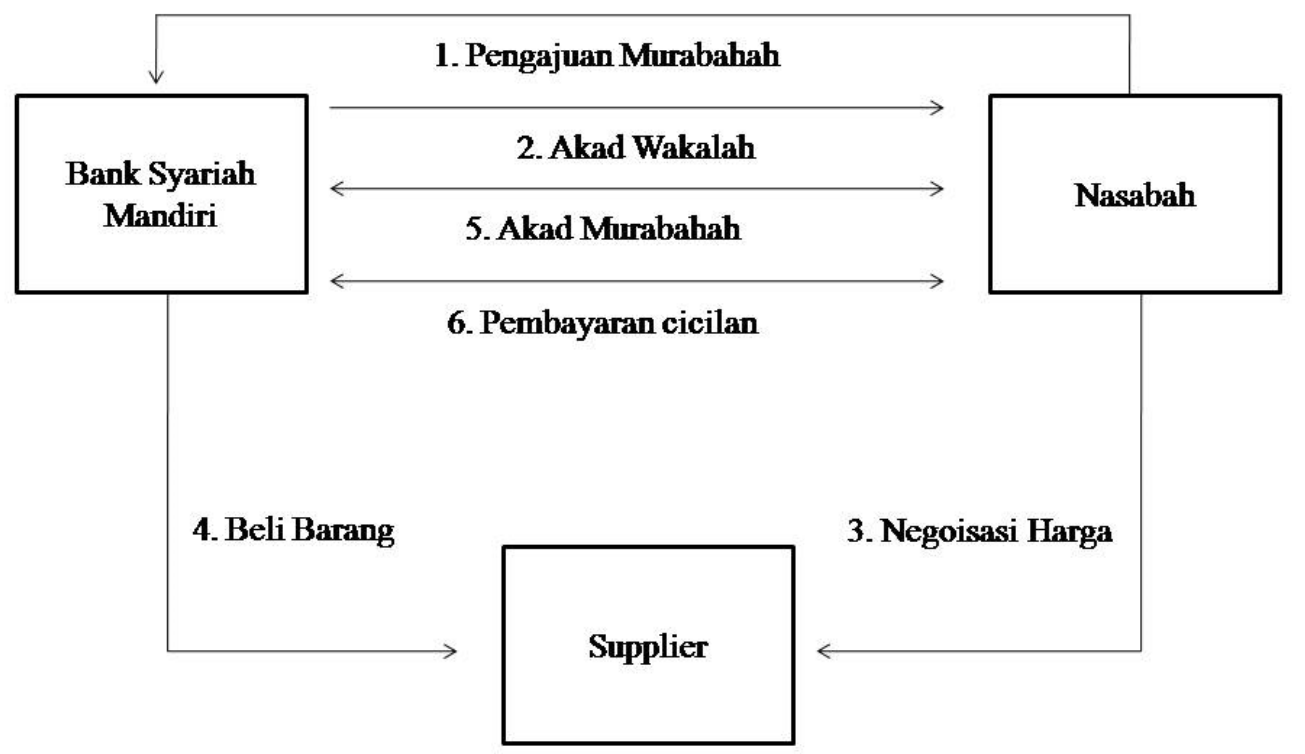

Gambar 2. Skema Akad Murabahah di Bank Syariah Mandiri Ponorogo

Keterangan:

1. Nasabah mendatangi bank untuk mengajukan pembiayaan murabahah dengan membawa kelengkapan dokumen-dokumen syarat pembiayaan.

2. Nasabah kemudian diuji kelayakannya, dan setelah disetujui bank memberikan kuasa kepada nasabah untuk melakukan negosiasi harga kepada pemasok.

3. Nasabah dan supplier melakukan negosiasi dan menyepakati harga barang yang diinginkan nasabah.

4. Bank mendatangi supplier untuk membelikan barang yang diinginkan oleh nasabah.

5. Setelah kepemilikan barang secara prinsip berpindah kepada bank, maka selanjutnya bank melakukan akad murabahah dengan nasabah dan menyepakati harga jual dan cara pembayaran yang dipilih oleh nasabah.

6. Nasabah melunasi pembiayaan kepada bank secara tunai maupun kredit.

Sebelum melakukan akad murabahah pihak bank melakukan uji kelayakan nasabah dengan analisis 5C kemudian bank melakukan survei lapangan yang dilakukan oleh pihak bank untuk memastikan kebenaran dokumen. Prinsip kehati-hatian dilakukan Bank Syariah Mandiri Ponorogo sebelum menerima permohonan pembiayaan dari nasabah untuk menghindari adanya kredit macet yang dapat merugikan pihak bank.

Aplikasi akad murabahah di Bank Syariah Mandiri Ponorogo berlandaskan fatwa No.04/DSN-MUI/IV 2000 tentang Murabahah. Poin 9 dalam fatwa ini menjelaskan bahwa akad murabahah boleh dilakukan setelah selesainya akad wakalah dimana barang telah menjadi milik bank secara prinsip.[27] Adanya akad wakalah dibutuhkan sebelum melakukan akad murabahah dengan tujuan mempermudah pihak nasabah untuk mendapatkan barang sesuai spesifikasi yang ia inginkan. Penggunaan akad wakalah juga mengurangi risiko pembatalan pembelian dari nasabah jika barang tidak sesuai dengan permintaan nasabah. Hal ini sesuai dengan prinsip tidak merugikan bank dan nasabah.

Akad wakalah yang digabungkan dengan akad murabahah di Bank Syariah Mandiri digunakan bank untuk memberi kuasa kepada nasabah untuk melakukan negosiasi dan 
menyepakati harga barang yang diinginkan nasabah.[28] Jika negosiasi dilakukan sendiri oleh nasabah maka nasabah akan mengetahui harga asli barang, biaya-biaya serta keuntungan yang diambil oleh bank sebagaimana karakter akad murabahah yaitu penjual harus menyampaikan hal-hal tersebut kepada nasabah. Selain agar nasabah mengetahui harga asli barang, Bank Syariah Mandiri Ponorogo menyadari bahwa pemberian kuasa kepada nasabah untuk pembelian barang yang diinginkannya akan berisiko pada kecurangan atau moral hazzard dalam penggunaan dana. Kecurangan dalam penggunaan dana oleh nasabah menyebabkan kerugian bagi bank.

\section{Kesimpulan}

Bank Syariah Mandiri Ponorogo memiliki sistem pengawasan internal yang optimal dan efektif untuk menghindari kecurangan dan pelanggaran terhadap kepatuhan syariah sebagai upaya agar bank dan nasabah tidak ada yang dirugikan. Dalam penerapan akad murabahah, Bank Syariah Mandiri Ponorogo mematuhi ketentuan fatwa No. 04/DSNMUI/IV/2000 tentang Murabahah, bahkan Bank Syariah Mandiri Ponorogo dalam mengaplikasikan akad murabahah "bil wakalah" memiliki inovasi yang bisa ditiru oleh bankbank syariah lainnya yaitu akad wakalah yang digunakan untuk negosiasi harga saja untuk meminimalisasi risiko penyalahgunaan dana oleh nasabah.

\section{References}

[1] Ascarya, Diana Yumanita, Bank Syariah: Gambaran Umum, (Jakarta: pusat Pendidikan dan Studi kebanksentralan (PPSK) Bank Indonesia, 2005) p. 1

[2] Ahmed H, Islamic Banking and Syariah Compliance: A product Development Perspektif. Journal of Islamic finance, V01.3, No.2, 2014, p. 15-29

[3] Ah. Azharuddin Lathif, "Konsep dan Aplikasi Akad Murabahah pada Perbankan Syariah di Indonesia”, Jurnal Ahkam, Vol. XII, No. 2, Juni 2012, p. 69-70

[4] Muhammad Umer Chapra Dan Ahmed. "Corporate Governance in Islamic Financial Intitutions,”Occasial Papper No. 6, Jedah: Islmaic Research\& Traning Institute/ Islamic Development Bank.

[5] Hafij Ullah, Shariah compliance in Islamic Banking An empirical study on selected Islamic Banks In Bangladesh, International Journal of Islamic And Middle Eastern finance And Management, Vol.7, No.2, 2014, p. 183

[6] Abdul Qowi Othman and Lynn Owen, "Adopting and Meusuring Customer service Quality (Sq) In Islamic Banking Industry: A study in Kuait Finance house, International Journal of Bussines and social science, Vol.3, No.1, p. 1

[7] Otoritas Jasa Keuangan, Roadmap Perbankan Syariah Indonesia 2015-2019, (departemen Perbakan Syariah, 2016), p.10 -11

[8] Ro'fah Setyowati, "Rasionalitas Pendekatan Sharia Compliance dalam Meningkatkan Kepercayaan nasabah Perbankan Syariah”, Jurnal Hukum Islam, Vol.1, No.1, Mei 2017, p.6

[9] Wulpiah, "Urgensi Penerapan Kepatuhan Syariah Pada Perbankan Syraiah ( Telaah konseptual- Analitis)", Asy- syar'iyah: Jurnal Ilmu Syari'iyah Dan Perbankan Islam, Vol. 2, No.1, 2007, p. 106- 108

[10] Islamic Financial Service Board (IFSB), Guiding Principles on Sharia Governance Systems for Institutions Offering Islamic Financial Services, Point 35, Desember 2009, p.3

[11] Bank Indonesia, Peraturan Bank Indonesia Nomor 13/2/PBI/ 2011 tentang Pelaksanaan fungsi Kepatuhan Bank Umum, Tanggal 12 Januari 2011 
[12] Ikatan Bankir Indonesia, Kepatuhan Dalam Bisnis Bank, ( Jakarta: Gramedia Pustaka Utama, 2014), p.5

[13] Lia Kian Syariah Compliace untuk Pengembangan Inovasi Produk Perbankan Syariah, http://uinjkt.academia.edu/LiaKian diakses 17 April 2017, jam 2.02 PM

[14] Imam al-'Alamah Ibnu Mandzur, Lisanul Arab, Cet-3, (Beirut: Dar Ehia al-Toutath alArabi, 1999), juz 5, p. 103

[15] Sofyan Sulaiman, "Penyimpangan Akad Murabahah Pada Perbankan Syariah di Indonesia”, Iqtishodia: Jurnal Ekonomi Syariah, Vol. 1, No. 2, September 2016, p. 9

[16] Abi Walid Muhammad bin Muhammad bin Ahmad bin Rusydi al-Qurthubi, Bidayatul Mujtahid wa Nihayatul Muqtashid, Cet-IV, Juz 2, (Beirut: Dar al-Ma'rifah, 1982), p. 213

[17] Yenti Afrida, "Analisis Pembiayaan Murabahah di Perbankan Syariah", JEBI (Jurnal Ekonomi dan Bisnis Islam), Vol. 1, No. 2, Juli-Desember 2016, p. 158

[18] QS. al-Baqarah: 275

[19] Ibnu Hajar al-'Asqalani, Subulu as-Salam Syarhu Bulughul Maram, Cet-I, (Riyadh: Maktabah al-Ma'arif, 2006), Kitab Buyu', Nomor Hadist 735, juz 3, p. 7

[20] al-Imam Abul Fida Ismail Ibnu Katsir ad-Damasyqi, Tafsir Ibnu Katsir, terj. Bahrun Abu Bakar, Cet-I, (Bandung: Sinar Baru Algensindo, 2000), juz 3, p. 141

[21] Bank Indonesia, Peraturan Bank Indonesia (PBI) No.10/18/PBI/2008 dan Butir 1 angka 4 SEBI No.10/34/DPBS/2008

[22] Bank Indonesia, Peraturan Bank Indonesia (PBI) No.5/21/PBI 2003 tentang Perubahan kedua Atas PBI No.3/10/PBI /2001 tentang penerapan prinsip mengenal nasabah

[23] Bank Indonesia, Peraturan Bank Indonesia (PBI) nomor 9/19/PBI/2007 jo Surat Edaran BI No. 10/14/DPbS tanggal 17 Maret 2008.

[24] Ismail, Perbankan Syariah, (Jakarta: Kencana, 2011), p. 139-140

[25] Bank Syariah Mandiri, Murabahah, dalam https://www.mandirisyariah.co.id/businessbanking/corporate/pembiayaan-investasi/murabahah, diakses pada 30 Juli 2019, Pukul $16: 24$

[26] Hasil wawancara dengan Branch Manager Bank Syariah Mandiri KCP Ponorogo, Bapak Moh. Ghani Wicaksono, Jum'at, 11:45 WIB, 24 Agustus 2018

[27] Fatwa Dewan Syariah Nasional, No. 04/DSN-MUI/IV/2000 tentang Murabahah, p. 4, dalam https://dsnmui.or.id/category/fatwa/, diakses pada 3 Maret 2018, pukul 22:35

[28] Hasil wawancara dengan Branch Manager Bank Syariah Mandiri KCP Ponorogo, Bapak Moh. Ghani Wicaksono, Jum'at, 12:06 WIB, 24 Agustus 2018 